\title{
Octave generalization of specific interference effects in memory for tonal pitch*
}

\author{
DIANA DEUTSCH \\ Center for Human Information Processing, University of California, San Diego \\ Box 109, La Jolla, California 92037
}

\begin{abstract}
An experiment is described which demonstrates that certain highly specific disruptive effects in immediate memory for tonal pitch generalize across octaves. Pitch recognition was required after a retention interval during which six other tones were played. The effects of including in the interpolated sequence tones which were removed by exactly an octave from those which had already been demonstrated to produce disruption were investigated. Generalization of these interference effects was found to result both from tones which were displaced an octave higher and (to a lesser extent) from tones which were displaced an octave lower. It is concluded that the memory store that retains information concerning the pitch of individual tones is bidimensional in nature, both "tone height" and "tone chroma" being represented.
\end{abstract}

Recently, certain highly specific interference effects in memory for tonal pitch have been demonstrated (Deutsch, 1970, 1972a, in press), and these are described below. By the use of a "mapping" technique, it has been shown possible to plot such effects specifically in microtonal intervals (Deutsch, 1972b). The results of this plot show a precise topographical distribution for such effects along a logarithmic scale. However, these experiments investigated effects within only a single octave.

This article concerns the question of whether the pitch memory store should be considered unidimensional in nature when it is explored beyond the octave. There are many reasons for supposing that this is not so. The traditional musical scale is based upon the octave, i.e., tones separated exactly by octaves are given the same name (C, C\#, D, etc.). The equivalence of tones separated by octaves is important in harmony, since chords made up of tones of the same name but in different octaves are treated as harmonically equivalent (Rimsky-Korsakov, 1930). Further, people with absolute pitch may often name a note correctly but place it in the wrong octave (Baird, 1917; Bachem, 1954). Experiments not only on man (Humphreys, 1939) but also on the rat (Blackwell \& Schlosberg, 1943) have demonstrated octave generalization in response to tonal stimuli. In addition, a complex tone made up of tones separated exactly by octaves sounds like a single organ-like tone rather than like a chord (which is the case with other tonal combinations). This has led to the production of a fascinating musical illusion. Shepard (1964) has generated a set of complex tones, each of which consists of several tones separated by octaves. When these tones are played going up the scale in semitone steps at

*This work was supported by United States Public Health Service Grants MH 21001-01 and MH 15828. I am indebted to R. Erickson, D. M. Green, and I. Pollack for their valuable discussions. I also thank D. A. Norman for use of computer facilities supported by United States Public Health Service Training Grant NS 07454-06 intervals of roughly one per second, the sequence is perceived as a set of single tones constantly ascending in pitch and never returning to the beginning. An analogous effect is achieved when the tones are played in descending semitone steps.

Because of the unique similarity of tones separated exactly by octaves, various investigators have maintained that pitch should not be treated as a unidimensional stimulus, but should, rather, be analyzed along two dimensions: tone height, which represents overall pitch level, and tone chroma, which defines the pitch of a tone within the octave (Meyer, 1904, 1914; Révés, 1913; Ruckmick, 1929; Bachem, 1948; Shepard, 1964). Various schemes have been suggested as a basis for such a bidimensional representation. Drobisch (1846) proposed that tonal pitch should be represented as a helix, with tones separated by exactly an octave lying in closest proximity within each turn of the helix. Ruckmick (1929) put forward a similar suggestion, but preferred a bell-shaped spiral to a helical representation. In a previous article (Deutsch, 1969), the present author suggested that pitch information traveled first to a unidimensional array (which would accommodate "tone height") and was from there relayed along two parallel channels. Along one of these channels, there is convergence from units separated exactly by octaves, and this therefore provides representation of an abstracted octave (or "tone chroma"). It should be added that such an abstracted octave array would best be represented as circular. The need for assuming a second channel, along which octave convergence does not take place, will be discussed later.

It is not the purpose of this paper to debate the merits of different suggested representations of "tone chroma," but rather to describe an investigation into whether immediate memory for tonal pitch should be considered unidimensional or bidimensional in nature. If interference effects which are specific within a single octave are shown also to generalize across octaves. then this is evidence for representation in immediate memory 
of the dimension described above as "tone chroma." However, if such generalization does not take place. it would appear that short-term storage of pitch information is unidimensional in nature, "tone height" alone being represented.

The two highly specific interference effects employed in the following experiment are shown to occur when pitch recognition is required after a time interval during which other tones are played. The first effect, described in Deutsch (1970. 1972a) demonstrates that when the standard (S) and comparison (C) tones differ in pitch. including in the intervening sequence a tone which is identical in pitch to the $\mathrm{C}$ tone, produces a substantial increase in errors. The second effect, described in Deutsch (in press) demonstrates that when the $\mathrm{S}$ and $\mathrm{C}$ tones are identical in pitch, including in the intervening sequence a tone a semitone removed from the $S$ (and $C$ ) tone, produces an increase in errors. A substantially greater increase in errors is produced when two tones. one a semitone below the $\mathrm{S}$ (and $\mathrm{C}$ ) tone and the other a semitone above it, are both included in the same intervening sequence. Since this cumulative effect is substantially more powerful than the interference due to just one critical intervening tone, two disruptive tones within the same intervening sequence were employed in investigating octave generalization of this second interference phenomenon in the experiment to be described.

\section{METHOD}

\section{Procedure}

In each condition. Ss listened to an $S$ tone, which was followed by a sequence of six intervening tones and then, after a pause, by a $C$ tone. All tones were $200 \mathrm{msec}$ in duration. The interval between the $S$ tone and the first intervening tone was $300 \mathrm{msec}$, as were the intervals between all the intervening tones. The interval between the last intervening tone and the $C$ tone was $2 \mathrm{sec}$. All tones were equal in loudness. The Ss were requested to listen to the $S$ tone, ignore the six intervening tones if they wished, and then to judge whether the $C$ tone was the same or different in pitch compared to the $S$ tone. Ss indicated their judgments on paper by writing " $S$ " (same) or " $D$ " (different).

\section{Conditions}

There were eight conditions in this experiment. In Conditions 14 , the $S$ and $C$ tones differed in pitch by a semitone. In Condition 1 (the first "null" condition), no tone of the same pitch as the $C$ tone or that was displaced from such a pitch by exactly an octave was included in the intervening sequence. In Condition 2, a tone of the same pitch as the $C$ tone was included in the second serial position of the intervening sequence. Condition 3 was the same as Condition 2, except that the critical included tone was displaced an octave higher. Condition 4 was the same as Condition 2, except that the critical included tone was displaced an octave lower.

In Conditions 5-8, the $S$ and $C$ tones were identical in pitch. In Condition 5 (the second "null" condition), no tone a semitone removed in pitch from the $S$ (and $C$ ) tone was included in the intervening sequence, and neither were any tones which were exactly an octave removed from these tones included. In
Condition 6 . there was included in the second serial position of the intervening sequence a tone which was a semitone higher in pitch than the $S$ (and $C$ ) tone. Further. there was included in the third serial position a tone which was a semitone lower. Condition 7 was the same as Condition 6. except that the two critical included tones were displaced an octave higher. Condition 8 was the same as Condition 6 , except that the two critical included tones were displaced an octave lower

The tape consisted of 80 sequences, which were presented in four groups of 20 . Sequences within each group were separated by 10 -sec pauses. A 5 -min break was incorporated between each group of sequences. The order of presentation of the sequences was random, with no separation by condition, except that each group of 20 sequences contained 10 in which the $S$ and $C$ tones were the same and 10 in which they were different: and each group of 20 contained just one example of each $S$ and $C$ tone combination. The Ss listened to the entire tape on 2 separate days, and their results were averaged.

\section{$\mathbf{S}$ and $\mathbf{C}$ Tones}

The $\mathrm{S}$ and $\mathrm{C}$ tones were taken from an equal-tempered scale (international pitch. $A=435$ ) and ranged from the $D$ a whole tone above middle $\mathrm{C}$ to the $\mathrm{B}$ almost an octave above. The frequencies used (in cps) were $\mathrm{D}=290 . \mathrm{D}=308, \mathrm{E}=326 . \mathrm{F}=$ $345, \mathrm{~F}=366, \mathrm{G}=388 . \mathrm{G}=411 . \mathrm{A}=435, \mathrm{~A}$ 프 $=461$. and $\mathrm{B}=$ 488. In all conditions, each of these tonal pitches was used equally often, either as an $S$ tone or as a $C$ tone, or as both. In Conditions 1-4, in which the $S$ and $C$ tones differed in pitch, in half of the sequences the $S$ tone was a semitone higher than the $\mathrm{C}$ tone and in the other half it was a semitone lower.

\section{Intervening Tones}

The intervening tonal pitches were taken from the scale described above, and they ranged over three octaves, from the $C$ \# almost an octave below middle $C(137 \mathrm{cps})$ to the $C$ two octaves above middle $C(1,035 \mathrm{cps})$. These pitches were chosen randomly, except as specified by the experimental conditions. with the following restrictions: No sequence contained more than one example of any tonal pitch or tones separated by exactly one or two octaves. No sequence contained a tone of the same pitch as the $S$ or $C$ tone of that sequence, or separated by exactly an octave from either of these. Further, each intervening sequence of six tones contained two tones taken from the lower octave, two from the middle octave, and two from the higher octave. The order of placement of these tones was random except as specified by the experimental conditions.

\section{Subjects}

Twenty-six undergraduates at the University of California at San Diego served as Ss in this experiment. They were selected on the basis of obtaining a score of at least $90 \%$ correct on a short tape containing sequences designed as in the "null" conditions. The Ss were paid for their services.

\section{Apparatus}

The tones were generated as sine waves by a Wavetek oscillator controlled by a PDP-9 computer, and the output was recorded on high-fidelity tape. The tape was played to Ss on a high-quality Wollensak tape recorder, the output of which was passed through a frequency balance control (Advent Corp.) and a Fisher Stereo Master Control amplifier. with the controls adjusted so that the tones were equal in apparent loudness. The output was played to the Ss through higl-quality $\mathrm{KLH}$ loudspeakers. 


\section{RESULTS}

The results of this experiment are shown in Table 1. It can be seen, by comparing Conditions 1 and 2 , that when the $\mathrm{S}$ and $\mathrm{C}$ tones differ in pitch, a substantial increase in errors is produced by including in the intervening sequence a tone which is identical in pitch to the $\mathrm{C}$ tone. This disruptive effect has already been demonstrated (Deutsch, 1970, 1972a) and is here significant on a Wilcoxon test (two-tailed) beyond the .01 level. Comparisons of Condition 1 with Conditions 3 and 4 demonstrate further that this disruptive effect also occurs when the critical intervening tone is displaced an octave higher (Condition 3) or an octave lower (Condition 4). For both comparisons, this increase in errors is significant on a Wilcoxon test beyond the .01 level (two-tailed). This disruptive effect on pitch discrimination therefore generalizes across octaves. In fact, the generalization from the higher octave is so great that the difference in errors between Conditions 2 and 3 is only just significant beyond the .05 level (two-tailed, on a Wilcoxon test). Generalization from the lower octave is weaker, and the difference in errors between Conditions 2 and 4 is significant beyond the .01 level (two-tailed, on a Wilcoxon test). In fact, errors when the disruptive tone is displaced an octave higher (Condition 3) are significantly greater than when this tone is displaced an octave lower (Condition 4), beyond the .02 level (two-tailed, on a Wilcoxon test).

An analogous pattern of octave generalization for the interference effect on recognition of the same tone is manifest upon comparing Conditions 5-8. Comparison of Conditions 5 and 6 shows that a large increment in errors is produced by including in the intervening sequence two tones, one a semitone higher and the other a semitone lower than the $\mathrm{S}$ tone. This effect has also been demonstrated elsewhere (Deutsch, in press) and is here significant on a Wilcoxon test beyond the .01 level (two-tailed). Comparisons of Condition 5 with Conditions 7 and 8 demonstrate that this interference effect also occurs when the critical intervening tones are displaced an octave higher (Condition 7) or an octave lower (Condition 8). For both comparisons, the increment in errors is significant on a Wilcoxon test beyond the .01 level (two-tailed). This specific interference effect therefore also generalizes across octaves. Here, the generalization from the higher octave is so great that no significant difference in errors is manifest between Conditions 6 and 7 (p>.05, two-tailed, on a Wilcoxon test). However, as with the disruptive effect on tonal discrimination described above, the generalization from the lower octave is weaker. Significantly fewer errors are made in Condition 8 than in Condition $6(p<.01$, two-tailed, on a Wilcoxon test), and fewer even in Condition 8 than in Condition $7(p<.01$, two-tailed, on a Wilcoxon test $)$.
Table 1

Percentage Errors in the Different Conditions of the Experiment

\begin{tabular}{rr}
\hline Percentage \\
Errors
\end{tabular}

$\mathrm{S}$ and $\mathrm{C}$ Tones Different

1 No tone at pitch of $\mathrm{C}$ tone, or displaced by an octave from $\mathrm{C}$ tone, included in intervening sequence.

2 Tone at pitch of $\mathrm{C}$ tone included in intervening sequence.

3 Critical included tone as in Condition 2, but displaced an octave higher.

4 Critical included tone as in Condition 2, but displaced an octave lower.

$S$ and $C$ Tones Same

5 No tone a semitone removed from $S$ (and $C$ ) tone, or displaced from such a tone by an octave, included in intervening sequence.

6 Two tones, one a semitone higher and the other a semitone lower, included in intervening sequence.

7 Critical included tones as in Condition 6, but displaced an octave higher.

8 Critical included tones as in Condition 6 , but displaced an octave lower.

\section{DISCUSSION}

The above experiment demonstrates that certain specific disruptive effects in immediate memory for tonal pitch generalize across octaves. This is true both when recognition of the same tonal pitch is involved, and also when discrimination of one tonal pitch from another is involved. This provides evidence that there is a representation in immediate memory store for pitch information of the dimension described by various investigators as "tone chroma," or of an abstracted octave (as discussed in the Introduction). The fact that such generalization is not complete shows that there is also a representation of tonal pitch in an absolute sense, i.e., "tone height." It would appear, therefore, that the immediate memory storage of tonal pitch is bidimensional in nature.

The asymmetry between generalization from the higher octave and from the lower octave requires comment. This was not due to differences in apparent loudness, since care was taken to ensure that the lower tones were equal in apparent loudness to the higher tones. One possible explanation is that the $S$ tone is held in memory, including as part of its representation its harmonic series. Intervening tones from the higher octave would then interfere with this harmonic representation more than intervening tones from the lower octave. This explanation is rendered unlikely by the fact that the tonal stimuli employed were sine waves, and aural harmonics at the sound levels used in this experiment can barely be detected, even with the use of 
sophisticated techniques (Egan \& Klumpp, 1951). A further suggestion is that the higher tones compel the attention more than the lower tones. This has been demoristrated in other situations (Broadbent, 1958). An alternative hypothesis concerns the relationship between the physical octave and the subjective octave. It has been shown (Ward, 1954) that not only is the subjective octave slightly larger than the physical octave, but the relationship between the two differ as a function of frequency. Such a discrepant relationship may account for the asymmetry in the generalization data. Alternatively, one may make the simple assumption that whatever the connections underlying octave generalization, those from the lower to the middle octave are weaker than those from the higher to the middle octave.

It should not be concluded from this experiment, however, that octave generalization is a universal characteristic in memory for music. The above experiment shows that it holds true when judgments of isolated tones are involved. The general study of music leads also to the assumption that it holds for simultaneous tonal combinations (Rimsky-Korsakov, 1930). But memory for melody is a separate case. A tune is essentially a string of successive intervals. When these intervals are turned upside down (i.e., when one component tone is placed on the other side of the pitch continuum relative to the other component tone), they turn into different intervals. That is, a "third" becomes a "six th," a "fourth" becomes a "fifth," and so on. It was recently shown (Deutsch, 1972c) that the first half of the tune "Yankee Doodle" was not recognized when its component tones were placed randomly in any of three octaves. It has been suggested that this finding is due to "rhythmic fission" (Dowling, 1968) or "primary auditory stream segregation" (Bregman \& Campbell, 1971). These terms refer to the phenomenon that at high presentation rates, and when the successive tones are distant from each other along the frequency continuum, Ss have difficulty in reporting the order of tones in a sequence. However, the presentation rates used to obtain these effects are typically much faster than those employed in Deutsch (1972c) (Dowling, 1968; Bregman \& Campbell, 1971; Bregman, 1972; Wilcox, 1972). Furthermore, recent observations have shown that Ss experience the same difficulty in recognizing tunes when the component tones are placed randomly in any of three octaves, even with the use of presentation rates easily outside the range of the "primary auditory stream segregation" phenomenon (i.e., rates slower than $1 / \mathrm{sec})$. The results of the experiment described in Deutsch, 1972c are, however, consistent with the assumption that there is an independent channel for the processing of successive intervals along which octave generalization does not take place. This is not intended to imply that whole melodies do not generalize from one octave to another as they clearly do, both on the basis of common observation and as demonstrated by experiment (Francès. 1958). However. in such cases. the internal relationships within the melodies are transposed intact. so the abstracted successive intervals are preserved. Such a finding would be expected on the theory of music recognition proposed in Deutsch (1969).

At all events, it is concluded from the experiment described in the present article that the memory store which retains information concerning the pitch of individual tones should be considered bidimensional in nature both "tone height" and "tone chroma" being represented.

\section{REFERENCES}

Bachem, A. Note on Neu's review of the literature on absolute pitch. Psychological Bulletin, 1948, 45, 161-162.

Bachem, A. Time factors in relative and absolute pitch determination. Journal of the Acoustical Society of America, 1954, 26, 751-753.

Baird, J. W. Memory for absolute pitch; Studies in psychology. In Titchener commemorative iolume. Worcester, 1971. P. 69.

Blackwell, H. R., \& Schlosberg, H. Octave generalization. pitch discrimination. and loudness thresholds in the white rat. Journal of Experimental Psychology, 1943, 33, 407-419.

Bregman, A. S. Effects of stream segregation on the perception of order. Paper given in a symposium entitled. "Perception of temporal order in hearing: Old pattern recognition problems in a new guise," at the American Psychological Association meeting, Honolulu, Hawaii, September 1972

Bregman, A. S., \& Campbell, J. Primary auditory stream segregation and perception of order in rapid sequence of tones. Journal of Experimental Psychology, 1971. 89, 244-249.

Broadbent, D. E. Perception and communication. London: Pergamon Press, 1958.

Deutsch, D. Music recognition. Psychological Review, 1969. 76. 300-307.

Deutsch, D. Dislocation of tones in a musical sequence: A memory illusion. Nature, 1970, 5242, 226.

Deutsch, D. Effect of repetition of standard and comparison tones on recognition memory for pitch. Journal of Experimental Psychology, 1972a, 93, 156-162.

Deutsch, D. Mapping of interactions in the pitch memory store. Science, 1972b, 175, 1020-1022.

Deutsch. D. Octave generalization and tune recognition. Perception \& Psychophysics, 1972c, 11, 411-412.

Deutsch, D. Interference in memory between tones adjacent in the musical scale. Journal of Experimental Psychology, in press.

Dowling, W. J. Rhythmic fission and perceptual organization. Journal of the Acoustical Society of America, 1968, 44, 369. (Abstract)

Drobisch, M. W. Über die mathematische Bestimmung der musikalischen Intervalle. 1846. Also, Abh. d. kgl. sächs. Ges. d. Wiss. math.-phys. Cl.b.II. $1855,35$.

Egan, J. P., \& Klumpp, R. G. The error due to masking in the measurement of aural harmonics by the method of best beats. Journal of the Acoustical Society of America. 1951, 23, 275-286.

Francès, R. La perception de la musique. Paris: Vrin, 1968.

Humphreys, L. F, Generalization as a function of method of reinforcement. Journal of Experimental Psychology, 1939. $25,361-372$.

Meyer, M. On the attributes of the sensations. Pyrchological Review. 1904. 11,83-103. 
Meyer. M. Review of G. Révés. "Zur Grundleguncy der Tonpsychologie." Psychological Bulletin. 1914, 11, 349-352.

Révés. G. Zur Grundleguncy der Tonpsychologie. Leipzig: Feit, 1913.

Rimsky-Korsakov, N. Practial manual of harmony. (12th ed.) New York: Fischer, 1930.

Ruckmick, C. A. A new classification of tonal qualities. Psychological Review, 1929, 36, 172-180.

Shepard, R. N. Circularity in judgments of relative pitch. Journal of the Acoustical Society of America, 1964, 36, 2345-2353.
Ward, W. D. Subjective musical pitch. Journal of the Acoustical Society of America, 1954, 26, 369-380.

Wilcox, G. W. Temporal coherence of tone sequences. Paper given in a symposium entitled, "Perception of temporal order in hearing: Old pattern recognition problems in a new guise." at the American Psychological Association meeting, Honolulu, Hawaii, September, 1972.

(Received for publication October 4, 1972; revisions received November 28,1972 .) 